\title{
Higher Education's Panopticon? Learning Analytics, Ethics and Student Engagement
}

Julie Wintrup, ${ }^{1}{ }^{*}$

Email J.Wintrup@soton.ac.uk

${ }^{1}$ University of Southampton, Highfield Campus, Southampton, SO17

1BJ UK

\section{Abstract}

Is learning analytics a movement that seeks to rebalance the effects of higher education's apparent blindness to privilege, its unequal access regimes and persistent retention and attainment gaps through a more skilful and strategic use of student data? Or is it part of a larger project to surveil students and staff in higher education, in pursuit of greater efficiency and control? Both perspectives are alive and well in debates surrounding higher education's changing relationship with its students. The systematic institutional use of student-generated data known as learning analytics is raising practical, methodological and ethical questions, which are yet to be answered. However, a proposed framework for assessing and comparing the quality of learning and teaching in the UK is poised to use such data as one of its metrics. Learning analytics and its relationship to student engagement is explored through the first known research to utilise an adaptation of Kuh's National Survey of Student Engagement with people studying Massive Open Online Courses. Contrasting perspectives are offered by Siemen's theory of connectivist learning and Foucault's notion of the panopticon. If the potential of analytics is to be realised in terms of meaningful quality improvement, questions remain concerning ethics, trust, its role in engagement in learning, and the ways in which policy might effectively safeguard the longer-term individual and collective interests of students.

\section{Keywords}


learning analytics

MOOCs

student engagement

ethics

student data

\section{Introduction}

In the UK, a new national framework that enables the assessment and comparison of teaching quality across higher education (HE) institutions is proposed. Early work on the Teaching Excellence Framework, or TEF, has identified three readily available systems of measurement likely to be used as indicators of quality: (1) students' progression and retention; (2) graduates' employment and earnings; (3) and student satisfaction ratings (Department for Innovation, Business and Skills, 2015). Translating such an ambitious political project into policy that is capable of effecting change is complex. Implementation requires an examination and prioritisation of the relationships between institutional values, missions, policies and regulations, as well as disciplinary/professional codes and legislation, the creation of policy statements and standards that are measurable and auditable, described by Saunders (2011) as education practices. Competing priorities mean decisions may have to be made between, for example, whether to select students in traditional qualification-based ways, or in ways that promote the ongoing project to widen access to education (Moore et al., 2013), or by using new forms of evidence to predict which applicants are likely to remain on course or achieve high grades (Simon, 2016). Offering programmes most likely to secure highly paid employment is also likely to be a consideration for $\mathrm{HE}$ providers in a marketised environment (Brown and Carasso, 2013).

Political initiatives such as the TEF introduce risky and potentially destabilising outcomes - when the new metrics were used to rank institutions retrospectively, a very different hierarchy emerged (Havergal, 2016a). They also serve to remind us that students do not conform to the consumer role so often described, but are frequently active, influential agents, colleagues and stakeholders in HE (Bovill et al., 2011). Moving from idea to policy formation and to education practices requires behaviour changes at all levels of the institution, including among students. Attempts to simply 'game' the system rather than to seek new ways to improve education quality and outcomes across the board, will most likely be recognised as such (Greatbatch 
and Holland, 2016). I make the assumption throughout this article that if the use of student data is to gain acceptance and be considered reliable and meaningful in everyday education practices in learning organisations (Senge, 1990 ), it needs to be generated and collected unobtrusively yet explicitly, effectively, ethically and legally, with the involvement and understanding of students and staff.

For the purposes of examining the relationships between analytics, ethics and student engagement, I want to begin by accepting the stated ambition of the TEF project — to improve learning and teaching quality — and set to one side wider criticisms for the time being (such as those made by Forstenzer, 2016). This objective, viewed from a pedagogic and policy perspective rather than a narrow technological one, requires a preparedness to grapple with both the means and ends of learning analytics as a project. Inevitably intertwined, these include such things as the methods of data collection, analysis and interpretation, the many ways in which findings are useful to education practice, and the implications, risks and opportunities presented, particularly to students. 
It is often said that policy lags behind technological change, producing risks (Burn-Murdoch, 2013). Innovation often presents us with a fait accompli, shifting the debate into how new and unanticipated circumstances are managed, before agreement is reached on whether the new state is desirable. The recent experience of the UK's National Health Service (NHS) has particular relevance to debates surrounding the ethics and acceptability of large-scale data collection. Government proposals that all patients' data be stored in a single database offered such uncontested benefits as safer approaches to treating individuals, the identification of clusters of illness or new patterns and trends, and new possibilities for diagnoses and public health interventions (National Data Guardian, 2016). However, the project had to be abandoned after considerable financial investment, when the National Data Guardian ruled that insufficient protection for individuals had been built into plans, resulting in a damaging lack of trust (National Data Guardian, 2016). Dame Fiona Caldicott stated:

Exciting though this all is, we will throw away these opportunities if the public do not believe they can trust us to look after their medical data securely. The NHS has not yet won the public's trust in an area that is vital for the future of patient care- (National Data Guardian, 2016, 2).

While there are clear differences between sensitive health data and freely given information such as satisfaction ratings or employment status and earnings, there are similarities when students' personal online activity and data are included.

In a similar vein, I want to briefly introduce the term 'student engagement', its use in analytics literature and how this differs from more established notions of engagement. In reports and research into learning analytics, the term 'student engagement' is used to describe online interactions with educational resources - from completing an online test to downloading an article (Nelson, 2014). This is in contrast to the way engagement in learning has been researched and theorised, predominantly in campus and classroom-based education settings, by researchers interested in more intellectual and social forms of engagement associated with high quality education. I draw on the influential work of Kuh (2001) and Kuh et al. (2010) and Gibbs (2012), the important connectivist theory of Siemens (2005), and the critical perspective offered by Foucault's (1975) notion of the 
panopticon, in an attempt to reflect the fusion of political intervention, classroom-based learning and digital innovation characterising much of our current education provision.

AQ1

\section{Progression, Retention and Ideas of Engagement}

Of the three TEF criteria, assessing and comparing student progression and retention is the most difficult to measure of the three and is of most interest in terms of student engagement in learning. Yorke (2013) describes the complexities of capturing what he considers to be reliable student assessment data over extended periods of time, and emphasises the importance of understanding the nature of different programmes and modes of study. Even when contextual knowledge and data are available, quality is a contested concept. Ashwin $(2014,123)$ asserts inadequate attention is paid to the importance of the 'relations between knowledge and curriculum' when seeking to define quality. Disciplinary differences are emphasised by Buckley's (2014) research into student engagement, suggesting disciplinary requirements and methods elicit in learners different forms of intellectual and social engagement. Nonetheless, the political requirement for a form of stable and comparative data, adequate for the purpose of denoting aspects of quality across courses and institutions means that learning analytics are set to become increasingly important to strategists in HE, regardless of more nuanced research evidence.

Still a relatively new and evolving concept in HE, most educators would recognise learning analytics as the capture and use of data generated by students working within a particular virtual platform, such as students' use of resources and their interactions with assessment activities. Considerable investment has been made both by the UK government and by several universities (especially the Open University, see for example Havergal, $2016 \mathrm{~b}$ ) in new systems that are able to capture and analyse student data for these broad, learning and teaching improvement purposes (Sclater et al., 2016). Long and Siemens (2011) differentiate this form of data and its direct relationship with individual students, from the institutional 'big data', that combines a variety of types of student data generated by such things as swipe cards, use of the internet and social media, while asserting both have a contribution to make to reducing attrition or 'drop out' in education.

Policy makers and scholars today are building on many decades of work that 
has sought to understand and reduce dropout. The work of Tinto (1975, 1998 ) continues to influence how the relationships between student, learning and teaching approaches, and the institution are conceptualised and researched, most notably through the work of Kuh (2001) and Kuh et al. (2010) in the form of the National Student Survey of Engagement (NSSE). Learning analytics' proponents identify with this body of work despite radically different origins in traditional, classroom-based HE (Robinson, 2012). Siemen's (2005) connectivist theory of how learning takes place in a digitally connected world is helpful in framing an exploration into analytics, ethics and engagement, as it presupposes a democratic ethos (Dewey, 1916); that is, learning takes place inside and outside of formal study, in communities, and is intrinsically learner-directed, spontaneous, experimental and situated. For Dewey (1916), education is successful when it leads to the desire to keep learning.

The relationship between analytics and student engagement is evident when pedagogy, hardware and technology are symbiotic; the 'flipped classroom' (Abeysekera and Dawson, 2015), the rehearsal of knowledge through online tests (Hunter Revell and McCurry, 2012), and virtual project work (Dickey, 2005 ) show how technology is already shaping new forms of student involvement in learning in traditional classroom settings. Freeman and Plassman (2015) offer a typical approach to using analytics to improve individual learning by developing online course work with feedback loops to signal difficulties or poor test results, and offer opportunities for rehearsal and improvement. Such uses reflect Long and Siemen's (2011) assumptions that use of analytics has potential to enhance individual learning.

What might be called small data — generated by an individual, group or cohort - becomes big data in terms of quantity, or when combined with other forms of student-generated data, and when it is made use of by the institution (Sclater, 2014). Massive Open Online Courses (MOOCs) with their hundreds of thousands of learners gave impetus to big data research and is interesting to researchers because of the quantity produced (Daries et al., 2014). In all its forms, learning analytics offers new possibilities for actionable intelligence (Ferguson and Shum, 2013) as we move from anecdote and experience, to analysis of trends and patterns evidenced over time, increasingly amenable to fine grained analysis and ultimately reveals key points for educational intervention. Progression information (students' entry qualifications, grades, absences, final classifications and so on) can be analysed, for example, in 
relationship to the formal curriculum, or by student characteristics, or for course and institutional benchmarking purposes. While these are not new concepts, an effective institutional system of analytics means questions can be answered in seconds and 'data mining' (asking specific questions of large datasets) is made possible, for managerial and business purposes as well as educational improvement goals (Baepler and Murdoch, 2010).

Two interrelated uses of analytics are emerging then: one use is the capture of individual and cohort/group student data with the purpose of personalising and automating feedback systems to improve learning and teaching; and the other is the capture and analysis of 'big data', to learn about institutional behaviours, trends, patterns and to make predictions. Long and Siemens (2011) summarise these as helping educators to improve teaching and learning, and guiding reform in HE.

In the UK, Sclater (2014) recently extended definitions of learning analytics to include not only digital evidence of students' online activity but also all data captured by HEIs on students and staff; that is, big data. The inclusion of swipe card data, the receipt of and responses to automated emails, demographic data, entry qualifications and so on is significant given broader political requirements. For example, monitoring of swipe cards to access buildings and rooms satisfies the UK Home Office requirement for international students' presence on campus to be evidenced and subsequent drop out reduced or prevented (Home Office, 2016). More controversially, the UK government's 'prevent strategy' requires HEIs to implement 'robust procedures both internally and externally for sharing information about vulnerable individuals' (HM Government, 2014, 18). Should the TEF be included in national and international ranking systems, new pressures to identify (and potentially to exclude) students most likely to drop out of education early will shape policy (Department for Innovation, Business and Skills, 2015).

While commercially rational, such decisions carry risks to individuals and groups who might be identified as 'at risk' or 'vulnerable'. Such terminology lends a moral force to remedial, deficit-focussed interventions by the institution and to the monitoring of individuals. Loosely articulated notions of engagement, online activity and progression imply a more robust relationship with established research into engagement than is evident from the analytics literature. For these reasons I suggest new questions are raised for students and educators, with implications for relationships, learning and teaching 
approaches, and most importantly for the kind of education communities of practice we wish to create.

\section{Analytics, MOOCs and Student Engagement}

Analytics as a field of education research and data mining has been boosted by the emergence of Massive Open Online Courses (MOOCs) and in the UK by the development of an international collaboration (FutureLearn) led by the Open University (Sharples et al., 2015). The freedom offered by MOOCs is in contrast to the complicated obligations and relationships described by participants in Rose-Adams' (2012) research into drop out. They generate a form of big data, useful for business and commercial purposes as well as pedagogic research. Hall (2012) suggests that when education is constructed as a transaction, interaction with online materials is, in itself, a form of customer feedback. MOOCs straddle commercial and pedagogic agendas, with learning analytics positioned as an indicator of both customer feedback and student engagement (Nelson, 2014). So when, in 2014, the UK Higher Education Academy commissioned research into two early UK MOOCs, we were presented with an opportunity to explore Kuh's (2001) concepts of student engagement with MOOC learners. As a research team we combined interests in technology, education innovation and student engagement, and together we saw MOOC learners as the epitome of the engaged learner self-directed, situated in work and social worlds, studying without obligations or formal assessments, and, possibly, for the love of learning and for personal development. Downes (2015) said of the free-form, un-assessed (connectivist) MOOC: 'Each bit of experience, each frustrated facing of a new chaos, changes you, shapes you' (blogpost).

Two linked studies were commissioned. In the first we explored how MOOC learners assessed their engagement in learning using an adapted form of the United Kingdom Engagement Survey (UKES) (Buckley, 2015) and demographic data (Wintrup et al., 2015a). We gained permission from the Trustees of Indiana University to further adapt NSSE items for use with MOOCs, making it the first ever adaptation of the tool that we were aware of to investigate forms of engagement among this group. The NSSE has been adapted globally and is used in Ireland, Australia, Africa and most recently the UK, in the form of the UKES (Buckley, 2013). The survey asks students to think in more reflexive ways about their relationship with their education; for example, how often social and peer learning has occurred, whether they feel intellectually stretched, and to what degree they have been able to direct 
their own projects and ideas. Gibbs (2012) considers the NSSE to be the most valuable indicator of what has come to be called 'learning gain', as it explores students' insights into both the processes of learning and their own development.

In the second study, we interviewed ten participants who volunteered via the online survey (Wintrup et al., 2015b). All had completed the six-week-long courses so in Nelson's (2014) sense were highly engaged. In addition, they reflected the typical pattern of engagement created by the MOOC UKES research, so in Kuh's (2001) sense were also intellectually engaged. Each was selected purposively according to their education, occupation and demographic profiles, to provide a diversity of perspectives. The two studies, already reported separately, together offer helpful insights into the meaning of engagement to individuals who felt highly involved and energised, and described being part of a group, although they had never met each other or course tutors. Their UKES ratings allowed us to explore with individuals the particular aspects of their learning they had rated as highly engaging and to understand how, in their own words, they maintained involvement, used learning resources and technology, and applied MOOC learning to their lives. We heard a good deal about a passion for learning ('I'm addicted now') often developed later in life, and the conditions that made possible unfettered, uncomplicated relationships to ideas and knowledge. These conversations were particularly useful in identifying what was not - and could not be captured either by the standardised UKES, or by the digital analytic footprints left on the MOOC platform - the interactions and experiences Long and Siemens (2011) considered lost forever — yet illustrated connectivist forms of engagement.

The UKES survey elicited responses from 974 people studying in 35 countries, aged from 17 to over 65 years of age. Regardless of prior educational attainment, very good and excellent levels of engagement were reported in such intellectual endeavours as:

- forming new understandings;

- making judgements and evaluating material;

- reflecting, integrating and connecting ideas with previous learning and experiences, and changing ways of understanding issues;

- and critical engagement with research, in particular methods and results 
(Wintrup et al., 2015a, 25-33).

Fewer reported engaging in social, collaborative or applied learning, as might be expected from an online course, although those who did often described forms of social media outside the MOOC platform. The survey item describing engagement with research elicited reports of higher levels of engagement among our MOOC learners than those levels reported by students who had attended traditional three year, taught courses, normally campus based, in HE institutions (Wintrup et al., 2015a; Buckley, 2014).

Interview participants variously described research as discovery, as work, and as an attitude or approach to learning (Wintrup et al., 2015b). Not included in our earlier reports, their insights reveal the ways they experienced connectivism and engagement, used a variety of devices and actively sought out and developed new networks. Other than a shared commitment to 'keeping up', very different ways of engaging in learning were described. For one participant, a retired nurse, research and methods came to life for her through late night Facebook discussions with a fellow MOOC learner living on a small Pacific island. His personal and compelling descriptions of the effects of disastrous mining practices on his home and community meant she was able to connect research, political decisions and lived experience in a way that transformed her understanding and knowledge. Following up the conversation by reading a research article, she recalled feeling 'horrified ... at just how much damage we are doing to the sea bed, and its unnecessary damage as well'. The new insights motivated a wish to become involved in conservation activities: 'I really want to do some volunteering and help out'.

This sense of being part of an international community of learners - 'the global nature of it' - was often generated by familiar forms of social media, that institutional approaches to learning analytics would not be able to capture (primarily Facebook, Twitter or Google+ discussions). Indeed, the decision not to contribute to the online MOOC discussion forum concealed active social interactions and learning with fellow learners outside the designated education platform. An interview participant described how he learned through and with others online, epitomizing connectivist learning. Using train and car journeys, a mixture of devices, and a network of fellow MOOC learners interested in online 'games', he states: 'Every day is a learning experience really'. A mid-40s engineer, who left school to begin work and has since learned through non-graduate level work-based programmes, he 
described setting up a Google+ group with other learners, independent of and not monitored by MOOC tutors: 'There was a lot that went on between us, some of the resources that were shared on the Google+ group, just in terms of web articles that were relevant to the course, were brilliant, really fascinating reads ... if someone put one of those up I would always say thank you for it and make a comment'. His attitude to learning and technology is open and confident: 'I really have thrown myself into the web, I love technology and I love what the web has given us, I'm a very open person online. Some people are wary of it, of the security and privacy issues ... but sharing information is a benefit to so many people, and the advantages totally exceed any sort of risks associated with it'. For this MOOC learner, all these activities constitute research: 'if you have the interest, you can do the research'.

Other interview participants did not feel so confident using alternative forms of communication such as Google+: one considered it to be 'for more intellectual types' while another felt anxious about posting comments that might make her look foolish to other learners, despite using Facebook confidently. Another chose not to use any social media, acknowledging 'it excluded me partly from certain things'.

Despite the emphasis placed on tests and quizzes within MOOCs, 'clicking through' often reflected a wish to move on swiftly rather than rather than spend time checking memory or retention of facts: 'you've got to be self-motivated, you've got to click the button to say you've completed ... but I've skipped forward and if I need to, I go back later'. Despite the investment made by many educators to create videos, these were sometimes skipped, or watched while cooking or in other fairly passive ways. One interviewee commented: 'I'm not keen on videos, quite often they have transcripts and I read the transcript'. However reflecting earlier research (Bayne and Ross, 2014 ) educators were seen by interviewees as central to the success of a MOOC: at their best they were interested in shared concerns, encouraged persistence and stimulated new ways of learning: 'Which is very involving, very encouraging, we had a professor, she asked us questions, it was academics answering us all the time, so much trouble was taken'. Multitasking was common: a mid-30s doctoral student with a young child described an online discussion in which 'it was sometimes quite complex, and interesting, particularly literary theory and stuff and we would be watching Bob the Builder'. The same interviewee described network building, by studying a MOOC developed by academics at the local university: 'I'm 
interested in it because I live here and it's my local university, and if I do apply for work there and get an interview I can name drop a bit, I have all sorts of different motivations'.

Deepening of understanding, new perspectives of real-world problems and even behaviours and actions were described in interviews, yet analysis of online interactions within the MOOC would not have revealed or even indicated such changes were taking place. This is not surprising - learning as Boud et al. (1993) and others describe it is sensory, embodied, practical and situated, and as such is far from amenable to capture. Yet much of daily life is now experienced through technology, from political campaigning to health care support groups, so it is particularly important to think carefully about what we mean by 'engagement' and to ensure that the kind of measures we use are relevant to the processes and outcomes of learning that we are trying to encourage. So the two studies together suggest that even the most sophisticated capture and analysis of our highly engaged interview participants' online interactions, would offer only a partial picture and may have the potential to be misleading. First of all, self-report via the UKES showed the importance of differentiating between types of engagement in learning — for example, social learning was low, reflective learning was high - a consideration absent from learning analytics literature but potentially very important. Interviews revealed forms of engagement in issues and with people that connected knowledge, understanding and application, but which by their nature would leave no traces of what Long and Siemens $(2011,32)$ call 'digital footprints'. If analytics are to be used as an indication of engagement in HE, or to develop individual student profiles of participation and achievement, then many of the forms of engagement most redolent of connected, communal learning will inevitably remain absent from the analytics database. In addition, the conflation of all online activity with the idea of engagement, even when task completion is a more appropriate description, we risk shaping learning in directions unwelcome by learners and ultimately likely to elicit conforming and adaptive behaviours. Finally, interviews reflect the different degrees of confidence with the online medium and the very different degrees of preparedness to experiment and take risks. The MOOC learners had no need to be concerned about an online presence knowing (or at least assuming) that they were not being individually monitored. They were free to be involved on their own terms and in ways they chose. Such freedom was appreciated and commented upon frequently as intrinsic to their enjoyment of MOOC learning. 
In the research, then, it became clear that 'data' became meaningful and educationally useful only when learners (and subsequently educators) brought their own understandings and perspectives to bear. Analytics data on its own might usefully reflect transactional activities that, in turn, might or might not indicate deep learning, but is (at least at present) incapable of reflecting much of the more transformative learning reported by interviewees.

\section{Analytics and Ethics}

If the association between analytics in HE and student engagement is undermined, the ethical questions surrounding its use acquire a new urgency for policy makers and education providers. Contemporary notions of student engagement reflect criticality and a more active form of citizenship: for example, engagement in the world as critical being and agent (Barnett, 1997; Bovill et al., 2011). However, HE's need for evidence, if the TEF is to be implemented successfully, risks quality being defined by what can be measured, ultimately creating education that elicits behaviours rather than thought - although the attempt to capture emotions through webcams is underway (Havergal, 2016a). Macfarlane (2015) describes 'presenteeism' as a component of performativity, requiring punctuality and visibility, which analytics extend into the pseudo-private online space and potentially beyond into assumed-to-be private spaces and places. The language and techniques of analytics all too often reflect what Giroux calls a corporate-based ideology (Giroux, 2011). Yet analytics' espoused concern for students 'at risk' with its emphasis on intervention introduces new responsibilities and obligations on the part of educators. In their influential discussion of the potential for analytics to reform education, Long and Siemens (2011) make little mention of such concerns - possibly because, like our engineer MOOC learner, hisan open, trusting worldview and positive experiences confirm that the possibilities and benefits of analytics far outweigh the drawbacks and risks. The formality of UK HE, with its high tuition fees and contractual relationships with students emanates from a different, more bureaucratic and risk-averse tradition. The different perspectives and priorities highlight and serve to contrast the freedoms afforded by technology and the potential of powerful, competing organisations to control and subvert its use. The challenges posed to policy makers implementing the TEF criteria include the need to consider students' rights to privacy and unequal access to technological devices and software, as well as the legislative requirements and acceptability of the use of personal data. 
Such ethical issues are clearly a concern to those pioneering learning analytics. The potential for 'misunderstandings, misuse of data and adverse impacts on students' is acknowledged in a recent 'Code of Practice for Learning Analytics' report by Jisc, a UK not-for-profit organisation formerly called the Joint Information Systems Committee, that supports research into technology in HE (Sclater and Bailey, 2015), which recommends that full information and an opt-out clause ought to be offered to students. Yet exactly what forms of digital presence students can opt out of, or refuse to have collected, or what the technological implications of opting out are, remain obscure. Like our interviewees, many students bring an open and trusting mind-set and are unlikely to change their habits, while others risk missing out on interesting activities because of a more cautious attitude. Anyway, O'Neill $(2003,4)$ suggests 'wholly, specific consent' is impossible; to consider all possible sets of outcomes, their risks and possibilities, to weigh them against each other, to situate them and to compare their potential benefits and harms, in unknowable future circumstances, is beyond the scope even of analytics experts. Students might well ask, why bother trying to understand analytics? Gomer and Schraefel (2016) differentiate between meaningful consent and a passive acquiescence lacking understanding or assessment of potential consequences, asserting: 'Consentful interactions must, by definition, be intelligible to the user, and controllable' (Gomer and Schraefel, 2016, 2). Going further, the production of ethical codes has been critiqued as a 'legal fiction' by Epstein $(2006,342)$, providing the necessary cover for unethical activities, while providing protection for those in positions of power.

\section{Students' Interests}

So while students are encouraged to manage their public social media presence responsibly, these new and emerging forms of online identity are generally invisible to students themselves who may not have given meaningful consent for their data to be used for these new purposes. Worse still, the move to 'big data' and its inclusion of all data sources in HE means students using online resources, or MOOCs incorporated into formal modules, or social media groups via university portals, may believe themselves to be interacting freely outside monitored systems, only to discover at some future point that their data has been collected. Policy makers, struggling to keep up with the possibilities afforded by new systems, need to pay attention to students' concerns if they are not to risk developing systems rendered unacceptable and unusable at some future point, as the NHS has done. 
Consent and anonymity are compromised when analytics data are combined with such identifying characteristics as age, prior educational achievements or mode of study. For example, the only 45-year-old in a cohort of 18 year olds, or the part time student in a cohort of full timers, will not be anonymous if these characteristics are included even if other identifying details are removed. Triangulation of forms of data risk individual student profiles telling new stories. For example, a student who chooses not to make use of online resources may seem to be absent in the online environment. Even our most socially active interviewees, developing networks via Google+ and in their localities, would not have appeared in any institutional or platform-based analytics database. This may not be a problem while marks and progress are good, but should the same student have a crisis, or cause to complain or appeal some aspect of their education, a lack of online or on-campus presence may be viewed as evidence of poor engagement. Savvy students, availed of such knowledge, may be motivated to demonstrate an online presence simply to avoid such a possibility (Weinstein et al., 2000).

The means of translating into analytics practice HE's duties in terms of data protection, or for enacting ethical principles of privacy, respect, transparency and informed consent into technological and educational practices is as yet unclear. Sclater (2014) asked leaders in learning analytics in seventeen HEIs what ethical or legal issues are raised by their use of analytics. Generally interviewees thought there were few, there was 'general consensus' that students are comfortable with the information collected (Sclater, 2014, 6). Others thought there were new possibilities for greater fairness, for example with regard to tackling the persistent attainment gap amongst Black and Minority Ethnic (BME) groups. But institutions are already able to analyse their own statistics and 'knowing' the statistics has not brought about change. The argument that HE reproduces privilege, and needs a mirror to show it how unequal students' experiences are, is one that learning analytics has to work harder to explain and defend. The notion that the persistent gap in attainment, despite equal entry qualifications, between white and black/minority ethnic students (Stevenson, 2012) is somehow to be reduced through the use of analytics, is to forget that structural forms of oppression, implicit bias, and inequalities exist throughout the academy and will only be altered by radically different cultures and policies within HE.

Knowledge of 'types' of student profiles also brings new risks; institutions and course leaders will need to resist the temptation to exclude individuals or 
groups on the basis of characteristics associated with higher drop out or lower grades, if they are to adhere to their institutions' commitments and duties to meet widening participation requirements and equality legislation (Department for Business, Innovation and Skills, 2014). The fear of students being categorised collectively or individually in negative ways is raised by Young (2016) and Rosen (2016) in response to research into school academies that recommends, as a strategy for success, 'improving admissions' and 'excluding poor quality students'. If HE were to decide, overtly or covertly, to assess the 'quality' of students, analytics offers a ready-made calculus.

\section{Implications for Policy Makers}

So the introduction of the TEF has brought to the fore a need to understand the implications of new metrics, designed to measure 'quality education'. While there are broader concerns about the TEF project, I am interested here in three possible implications for policy makers and educators of new uses of student data, its relationship to student engagement and ethical concerns raised.

First of all, there are clearly forms of creative and connectivist engagement that do not, as yet, generate freely accessible data. Alternative forms of social media outside university systems (even if accessed via university portals) and students' private spaces, virtual and physical, I suggest, ought to be safeguarded both to protect privacy but also to offer space and scope for valued, experimental, social learning activities. Clarity for students offered at the point of online interactivity would enable more informed choices to be made regarding potential opt-in to (and opt-out of) university-controlled mechanisms, possibly in the form of a pop-up reminder. Dialogue regarding the ethical and legal issues raised by analytics and by personal online habits might usefully form part of formal and informal staff/student meetings and systems, possibly as standing items supported by training courses and online reminders.

Secondly, analytics may mislead us and even dilute the desire to learn, so pivotal to Dewey's (1916) concept of democratic education. By designing learning as tests of knowledge, or by encouraging students to compete with peers or an anonymised norm, or even with a personal best, we risk altering fundamentally their relationship with learning. These concerns bring me to Foucault's (1975) notion of panopticism and the unanticipated consequences 
of introducing surveillance into the educational arena. A metaphor drawn from Bentham's ( 1843 ) design for a prison, in which a single watchman is able to continually observe prisoners, Foucault $(1975,199)$ speculates on how behaviours might change when we believe we are being observed, whether or not we are at any given moment. He postulated that authorities operate most successfully when doing two things: creating a binary division and branding types of individuals. The language of policy can be seen to risk dividing students into two distinct categories and labelling them (such as vulnerable/robust, at risk of drop out/likely to persist, struggling/successful). Routine techniques of measuring, observing and supervising students in the so-called risky or vulnerable categories, while explicitly intending to offer supportive interventions, may lead to the student behaving as though $\mathrm{s} / \mathrm{he}$ is being observed and changing behaviours accordingly: 'He becomes the principal of his own subjection' (Foucault, 1975, 199).

New forms of self-regulating subjectivity, and self-monitoring behaviours have the potential to alter relationships between students, educators, institutions and with learning. If ideas of the value of education are oriented towards a transactional approach and being able to achieve goals only within in a restricted and prescribed domain, then relationships with ideas, knowledge and with peers and educators will be radically altered. Rather than learning to scrutinise and question process as well as outcomes (Gibbs, 2012), and having a healthily sceptical approach to prescribed texts and learning in and about the world in new ways, students who fear being categorised as vulnerable or at risk may conform to prescribed modes of behaviour in the ways Macfarlane (2015) describes. In turn educators focussing on individual success, achievement of goals, competitiveness and league table positions may come to subscribe to and design learning that is boundaried, prescribed and amenable to being monitored, neglecting the messier transforming power of connectivist and work-based types of learning that by its nature is unpredictable, situated, impossible to evidence and taking place in networks (Boud et al., 1993; Mann, 2005). In a perfectly governed, analytics-driven university, managers, administrators and academics would not only need to be fewer in number - like the single watchman — but would cede much of their work to students who regulate themselves.

Finally, and on condition we are able to make policy that prevents such subtle forms of surveillance becoming routine and invisible, the potential of analytics can be exploited in ways beneficial to students. These include the 
explicit engagement with networks and communities within formal curricula. Downes (2008), in a defence of the broad application of connectivist approaches, asserts: 'There is nothing in traditional institutions - except, perhaps, policy — that prevents this model from working'. The independence offered by online resources combined with the evidence of intellectual and social engagement offered by a data trail mean students and educators may choose to spend time on the process of learning (and assessment and so on) rather than on didactic transmission of content. Either might recognise patterns in activity and work on more productive study habits, or recognise when a threshold is encountered or overcome by others, or discover more or less valuable resources and media. Support to experiment with mobile devices and software, or learn with new people, offers an alternative to more dystopian views that neglect the potential for active resistance and creativity. Less exciting, but possibly more likely, is the potential for administrative, logistical or legal barriers; the lack of awareness of potential legal or ethical problems by Sclater's (2014) contributors is surprising.

While the technologies and policies are still nascent, those who have daily encounters with students, who design and develop courses and curricula, and who think carefully about the purpose of teaching in $\mathrm{HE}$, have an opportunity to ask how analytics are being introduced into their institutions. Taking seriously the requirements of law and of the requirement for meaningful consent in audit and research, as well as our moral obligations to potential and future students, means broadening the scope of learning and teaching responsibilities to include the political, legal and ethical use of learning analytics in HE.

\section{References}

Abeysekera, L. and Dawson, P. (2015) 'Motivation and cognitive load in the flipped classroom: definition, rationale and a call for research', Higher Education Research and Development 34(1): 1-14.

Ashwin, P. (2014) 'Knowledge, curriculum and student understanding in higher education', Higher Education 67(2): 123-126.

Baepler, P. and Murdoch, C.J. (2010) 'Academic analytics and data mining in higher education', International Journal Scholarship of Teaching and Learning 4(2): 17. 
Barnett, R. (1997) Higher Education: A critical business, Buckingham: SRHE/OU Press.

Bayne, S. and Ross, J. (2014) The pedagogy of the Massive Open Online Course: The UK view, York: Higher Education Academy.

Bentham, J. (1843) The Works of Jeremy Bentham, Vol. 4, John Bowring/Harvard: Tait. http://oll.libertyfund.org/titles/bentham-the-worksof-jeremy-bentham-vol-4, accessed 6 October 2016.

Boud, D., Cohen, R. and Walker, D. (1993) Using experience for learning, Buckingham: SRHE/OU.

Bovill, C., Cook-Sather, A. and Felten, P. (2011) 'Students as co-creators of teaching approaches, course design, and curricula: implications for academic developers', International Journal for Academic Development 16(2): 133-145.

Brown, R. and Carasso, H. (2013) Everything for Sale? The marketisation of UK Higher Education, London: Routledge.

Buckley, A. (2013) Engagement for Enhancement: Report of a UK survey pilot, York: Higher Education Academy.

Buckley, A. (2014) UK Engagement Survey 2014, York: Higher Education Academy.

Buckley, A. (2015) UKES 2015: Students' Perceptions of Skills Development, York: Higher Education Academy.

Burn-Murdoch, J. (2013) 'Data protection is in danger of lagging behind technological change', The Guardian, 12 April, https://www.theguardian.com/news/datablog/2013/apr/12/data-protectionlaw-lagging-behind-technology, accessed 29 September 2016.

Daries, J.P., Reich, J., Waldo, J., Young, E.M., Whittinghill, J., Ho, A.D., Seaton, D.T. and Chuang, I. (2014) 'Privacy, anonymity, and big data in the Social Sciences', Communications of the ACM 57(9): 56-63.

Department for Business, Innovation and Skills (2014) National Strategy 
for Access and Student Success in Higher Education, London: HMSO.

Department for Business, Innovation and Skills (2015) Fulfilling our Potential: Teaching Excellence, Social Mobility and Student Choice, London: HMSO.

Dewey, J. (1916/2007) Democracy and Education, Middlesex: The Echo Library.

Dickey, M.D. (2005) 'Three-dimensional virtual worlds and distance learning: two case studies of Active Worlds as a medium for distance education', British Journal of Educational Technology 36(3): 439-451.

Downes, S. (2008) Connectivism and its Critics: What Connectivism is not, http://www.downes.ca/post/53657, accessed 21 September 2016.

Downes, S. (2015) From MOOC to Personal Learning, http://www.downes.ca/post/64556, accessed 29 September 2016.

Epstein, M. (2006) 'Why effective consent presupposes autonomous authorisation: a counterorthodox argument', Journal of Medical Ethics 32(6): 342-345.

Ferguson and Shum (2013) FutureLearn Workshop: Learning Analytics, https://r3beccaf.wordpress.com/2013/07/10/futurelearn-workshop-learninganalytics/, accessed 19 June 2015.

Freeman, C. and Plassman, P. (2015) 'Using technology to monitor first year student attendance in their academic studies', Brookes eJournal of Learning and Teaching 7(1), http://bejlt.brookes.ac.uk/paper/usingtechnology-to-monitor-first-year-student-attendance-in-their-academicstudies/, accessed 27 April 2016.

Forstenzer, J. (2016) What is the Purpose of the Teaching Excellence Framework? Council for the Defence of British Universities, http://cdbu.org.uk/what-is-the-purpose-of-tef/, accessed 21 September 2016.

Foucault, M. (1975) Discipline and Punish: The Birth of the Prison, London: Penguin. 
Gibbs, G. (2012) Dimensions of Quality, York: Higher Education Academy.

Giroux, H.A. (2011) On critical Pedagogy, New York: Continuum International Publishing Group.

Gomer, R.C. and Schraefel, M.C. (2016) Consentful surveillance: supporting user understanding and control. Everyday Surveillance Workshop, CHI 2016; 8 May, San Jose, USA.

http://everydaysurveillance.com/ accessed 1 December 2016.

Greatbatch, D. and Holland, J. (2016) 'Teaching quality in Higher Education: Literature review and qualitative research', Department for Business, Innovation and Skills, https://www.gov.uk/government/uploads /system/uploads/attachment_data/file/524495/he-teaching-qualityliterature-review-qualitative-research.pdf, accessed 21 September 2016.

Hall, R. (2012) 'The Profit Motive is Threatening Education', University World News, 18 November.

Havergal, C. (2016a) 'Tracking Student Emotions 'Could Improve Online Retention', Times Higher Education, 21 April, https://www.timeshighereducation.com/news/tracking-student-emotionscould-improve-online-retention, accessed 21 September 2016.

Havergal, C. (2016b) 'Mock TEF Results Revealed: A New Hierarchy Emerges', Times Higher Education, 23 June, https://www.timeshighereducation.com/features/mock-teaching-excellenceframework-tef-results-revealed-a-new-hierarchy-emerges, accessed 21 September 2016.

Home Office (2016) Tier 4 of the Points Based System: Guidance for Sponsors, Document 3: Tier 4 Compliance, London: HMSO.

HM Government (2014) Prevent Duty Guidance: A Consultation, London: HMSO.

Hunter Revell, S.M. and McCurry, M.K. (2012) 'Effective pedagogies for teaching math to nursing students: A literature review', Nurse Education Today 33(2013): 1352-1356. 
Kuh, G. (2001) 'Assessing what really matters to student learning: inside the National Survey of Student Engagement', Change: The Magazine of Higher Learning 33(3): 10-17.

Kuh, G., Kinzie, J., Schuh, J. and Whitt, E. (2010) Student Success in College: Creating the Conditions that Matter, San Francisco: Jossey-Bass.

Long, P. and Siemens, G. (2011) 'Penetrating the fog: Analytics in learning and education, Educause Review 46(5): 31-40, http://er.educause.edu / /media/files/article-downloads/erm1151.pdf, accessed 21 September 2016.

Moore, J., Sanders, J. and Higham, L. (2013) A Literature Review of Research into Widening Participation to Higher Education: Report to HEFCE and OFFA, Bristol: HEFCE, https://www.gov.uk/government /uploads/system/uploads/attachment_data/file/524495/he-teaching-qualityliterature-review-qualitative-research.pdf, accessed 21 September 2016.

O’Neill, O. (2003) 'Some limits of informed consent', Journal of Medical Ethics 29(1): 4-7.

Macfarlane, B. (2015) 'Student performativity in higher education: converting learning as a private space into a public performance,' Higher Education Research and Development 34(2): 338-350.

Mann, S. (2005) 'Alienation in the learning environment: a failure of community', Studies in Higher Education 30(1): 43-55.

National Data Guardian (2016) National Data Guardian for Health and Care, Review of Data Security, Consent and Opt-Outs, https://www.gov.uk /government/uploads/system/uploads/attachment_data/file/535024/datasecurity-review.PDF, accessed 29 September 2016.

Nelson, S. (2014) 'Blog: Measuring Our First Eight Courses', https://about.futurelearn.com/blog/measuring-our-first-eight-courses/, accessed 19 June 2015.

Robinson, C. (2012) 'Student engagement: what does this mean in practice in the context of higher education institutions?' Journal of Applied Research in Higher Education 4(2): 94-108. 
Rose-Adams, J. (2012) Leaving University Early: A Research Report from the Back on Course Project, Back on Course, Milton Keynes: The Open University:

Rosen, M. (2016) The Secret's Out: Improve a Failing School by Throwing Out 'Poor Quality' Pupils!, http://michaelrosenblog.blogspot.fr/2016/04 /the-secrets-out-improve-failing-school.html, accessed 24 April 2016.

Saunders, M. (2011) 'Setting the scene: the four domains of evaluative practice in Higher Education', in M. Saunders, P. Trowler, and V. Bamber (eds.) Reconceptualising Evaluation in Higher Education: The Practice Turn, Maidenhead: McGraw-Hill/Open University Press, pp. 1-17.

Sclater, N. (2014) Learning Analytics: The Current State of Play in UK Higher and Further Education, Bristol: JISC, http://repository.jisc.ac.uk /5657/1/Learning_analytics_report.pdf, accessed 24 April 2016.

Sclater, N. and Bailey, P. (2015) Code of Practice for Learning Analytics, Bristol: JISC, https://www.jisc.ac.uk/sites/default/files /jd0040_code_of_practice_for_learning_analytics_190515_v1.pdf, accessed 19 June 2015.

Sclater, N., Webb, M. and Danson, M. (2016) The Future of Data-Driven Decision Making, Bristol: JISC, https://www.jisc.ac.uk/reports/the-futureof-data-driven-decision-making, accessed 12 July 2016.

Senge, P.M. (1990) The Fifth Discipline: The Art and Practice of the Learning Organisation, New York: Doubleday.

Sharples, M., Adams, A., Alozie, N., Ferguson, R., Fitzgerald, E., Gaved, M., McAndrew, P., Means, B., Remold, J., Rienties, B., Roschelle, J., Vogt, K., Whitelock, D. and Yarnall, L. (2015) Innovating Pedagogy 2015: Open University Report 4, Milton Keynes: The Open University.

Siemens, G. (2005) Connectivism: A Learning Theory for the Digital Age, http://www.itdl.org/journal/jan_05/article01.htm, accessed 21 September 2016.

Simon, C. (2016) 'Colleges Can Now Figure Out Which Students will be Successful-Even Before Classes Start', Business Insider UK, 28 June, 
http://uk.businessinsider.com/how-colleges-use-big-data-2016-6, accessed 21 September 2016.

Stevenson, J. (2012) Black and Minority Ethnic Student Degree Retention and Attainment, York: Higher Education Academy.

Tinto, V. (1975) 'Dropout from higher education: a theoretical synthesis of recent research', Review of Educational Research 45(1): 89-125.

Tinto, V. (1998) 'Colleges as communities: taking research on student persistence seriously', Review of Higher Education 21(2): 167-177.

Weinstein, C.E., Husman, J. and Dierking, D.R. (2000) Self Regulation Interventions with a focus on Learning Strategies, Handbook of Self Regulation, San Diego: Academic Press.

Wintrup, J., Wakefield, K. and Davis, H. (2015a) Engaged Learning in MOOCs: A Study Using the UK Engagement Survey, York: Higher Education Academy.

Wintrup, J., Wakefield, K., Morris, D. and Davis, H. (2015b) Liberating Learning: Experiences of MOOCs, York: Higher Education Academy.

Yorke, M. (2013) Do cross-sectional student assessment data make a reasonable proxy for longitudinal data? Assessment and Evaluation in Higher Education 38(8): 957-967

Young, L. (2016) 'Academies are Excluding 'Poor Quality Students'-Yet More Social Cleansing from the Conservative Government', Independent, 20 April. 